\section{Case Reports in Oncology}

\title{
Complete Remission of Recurrent Retroperitoneal Liposarcoma after the Administration of Gemcitabine and Docetaxel as First-Line Adjuvant Chemotherapy: A Case Report
}

\author{
Filipe Rocha Da Silva ${ }^{a, b} \quad$ Alan Vitor Jerônimo Lima ${ }^{a, b}$ \\ Erick Willian Rocha Pereira Albuquerque ${ }^{a, b}$ Carlos Augusto \\ Moreira-Silvac Nicole Maués Flexa De Oliveira ${ }^{a, d}$ \\ Jorge Alberto Langbeck Ohana ${ }^{\text {a, e }}$ Luís Eduardo Werneck Carvalho ${ }^{a}$ \\ aOncológica do Brasil - Learning and Research, Belém, Brazil; bUniversidade do Estado do \\ Pará, Belém, Brazil; 'Instituto de Patologia Cirúrgica e Molecular, Belém, Brazil; \\ ${ }^{d}$ Centro Universitário do Estado do Pará, Belém, Brazil; eUniversidade Federal do Pará, \\ Belém, Brazil
}

\section{Keywords}

Liposarcoma · Chemotherapy · Oncology

\begin{abstract}
Retroperitoneal liposarcoma is a rare type of cancer. Relapse after surgery is frequent, and relapsing tumors tend to be more aggressive and less differentiated each episode, worsening the prognosis. This report describes the case of a 42-year-old female diagnosed with retroperitoneal liposarcoma after complete tumor resection. At the 3-month follow-up, another expansive lipomatous mass in the retroperitoneal area almost the same size as the previous one was detected. The patient underwent a new surgery, followed by first-line treatment with a gemcitabine- and docetaxel-based regimen for 8 cycles. Finally, the patient achieved complete
\end{abstract}


tumor remission confirmed by $\mathrm{CT}$ after the end of the treatment proposed. Although recurrence is a well-known characteristic of this neoplasia, no other case with such a vast expansion of a new tumor shortly after complete resection was found in the literature.

(C) 2018 The Author(s)

Published by S. Karger AG, Basel

\section{Introduction}

Retroperitoneal liposarcoma is a rare neoplasia that accounts for $10-15 \%$ of the soft-tissue tumors [1-3]. The annual incidence is approximately 2.7 cases/million inhabitants [4]. Well-differentiated (WD) liposarcoma is the most common subtype, besides being the one with the slowest and more gradual progression [5].

The histologic subtype, growth rate, and size of the tumor are independent predictors for survival, specifically for liposarcomas, besides influencing the time to recurrence after surgical extraction [6-8]. Recurrence is the main factor to be highlighted in the postoperative follow-up of these patients [3, 9].

The average time for the first local recurrence varies between 39 and 45 months [6, 7]. If the growth rate of the tumor is higher than $1 \mathrm{~cm} /$ month, it is related to a major incidence of recurrence, the average described in the literature being $0.34 \mathrm{~cm} /$ month $[6,10]$.

The gold-standard treatment is surgical resection [11]. In unresectable tumors, there is no consensus in the literature about the best treatment option [12]. Treatment with gemcitabine- and docetaxel-based regimens demonstrated a clinical response up to $40 \%$ in highgrade soft-tissue sarcomas [11-14].

This study has the purpose of reporting the case of an individual with WD liposarcoma with early recurrence and a high growth rate $(5.3 \mathrm{~cm} / \mathrm{month})$ yet with a complete response to gemcitabine- and docetaxel-based adjuvant first-line chemotherapy.

\section{Case Presentation}

A 42-year-old female was admitted to an oncological service in January 2015 due to the presence of a lipomatous mass in the retroperitoneal area (T2bNXM0) observed in an abdominal computed tomography (CT) (Fig. 1a). The patient underwent a complete surgery in March of the same year.

The histopathological analysis of the specimen showed a tumor mass weighing $679 \mathrm{~g}$ and measuring $14.0 \times 10.0 \times 7.0 \mathrm{~cm}$, partially encapsulated, formed by a trabeculated and fibroelastic, shinny brown-yellow tissue with central cystifications (Fig. 2) and the proliferation of lipoblast-like cells and hypercellular areas, with pleomorphic cells of bizarre hyperchromatic nuclear figures with both poorly and well-differentiated areas. Immunohistochemical stains were positive for the expression of S-100, ki-67, MDM2, and CDK4 proteins, consistent with WD liposarcoma (Fig. 3a, b).

In June 2015, the patient was submitted to a CT (Fig. 1b) showing an expansive lipogenic retroperitoneal mass involving the posterior pararenal space, measuring $8.0 \times 16.0 \times 7.7 \mathrm{~cm}$ in the biggest diameter with fibrous tissue and septations. The expansive effect determined the anterior displacement of the renal parenchyma and the compression of the iliopsoas muscle.

Thereafter, the patient underwent a new excision of the tumor, and the histopathological examination presented a high-grade pleomorphic sarcoma (Fig. 3b) that weighed $486 \mathrm{~g}$ and 
measured $14.0 \times 12.0 \times 6.0 \mathrm{~cm}$, evidencing a growth rate of $5.3 \mathrm{~cm} / \mathrm{month}$. Due to the recurrence, the patient was initiated on a first-line chemotherapy regimen of gemcitabine (675 $\left.\mathrm{mg} / \mathrm{m}^{2}\right)$ and docetaxel $\left(100 \mathrm{mg} / \mathrm{m}^{2}\right)$ for 8 cycles, during which she developed toxicity grade 2 (headache). Complete remission was demonstrated by an abdominal CT follow-up after the 8th cycle (Fig. 1c). The patient is currently monitored through clinical follow-up with the oncology service and imaging scans showing no evidence of recurrent disease 8 months after the last cycle of chemotherapy.

\section{Discussion}

Time to relapse of the tumor in this report was only 3 months, while most of the studies observed 39-45 months for the first local relapse after surgery for WD liposarcoma [6, 7]. Another indispensable factor for the prognosis in this type of tumor is its growth rate, which was $5.3 \mathrm{~cm} /$ month in our patient; a value 15 times bigger compared to what is described in the literature $(0.34 \mathrm{~cm} /$ month) [10]. Once a WD liposarcoma has a low growth rate and a relatively long time until relapse, it is considered more aggressive [5, 15].

Surgery is considered the first-line treatment for WD liposarcoma. For patients with inoperable tumors, the prognosis depends on adjuvant treatments that are controversial discussed among authors [11-14]. First-line standard adjuvant chemotherapy with doxorubicin and ifosfamide shows a myriad of toxic effects, thus limiting its use. The second-line option is treatment with gemcitabine and docetaxel, which has demonstrated a complete clinical response in $30-45 \%$ of the cases in high-grade sarcomas and being the first-line therapy in the present report [11-14]. Despite this tendency in the literature, this regimen's complete clinical response is still not well described [13-15]. Thus, the complete response observed in this report suggests the priorization of this therapy as a first-line adjuvant chemotherapy [13-15].

Facing all discussed points, the present case is atypical when compared to the ones in the current literature because the tumor presented a short relapse time and a very high growth rate. Besides, as complete response was obtained after the first-line adjuvant chemotherapy with gemcitabine and docetaxel, which is described as controversial in the literature, further studies for a better understanding of the lines of treatment for this type of tumor are recommended. On the other hand, the debate is challenged by the rarity of the disease.

\section{Statement of Ethics}

Written informed consent was obtained from the patient for the publication of this case report and any accompanying images.

\section{Disclosure Statement}

The authors certify that they have no conflicts of interest to disclose in the subject matter discussed in this paper. 


\section{References}

1 Goldblum J. Enzinger and Weiss's Soft Tissue Tumors: Expert Consult: Online. Elsevier Health Sciences. 2013;1:1-9.

2 Ferrari A, Sultan I, Huang TT, Rodriguez-Galindo C, Shehadeh A, Meazza C et al. Soft tissue sarcoma across the age spectrum: a population-based study from the Surveillance Epidemiology and End Results database. Pediatr Blood Cancer. 2011 Dec;57(6):943-9.

3 Karadayi K, Yildiz C, Karakus S, Kurt A, Bozkurt B, Soylu S et al. Well-differentiated abdominal liposarcoma: experience of a tertiary care center. World J Surg Oncol. 2015 May;13(1):166.

4 Lawrence W Jr, Donegan WL, Natarajan N, Mettlin C, Beart R, Winchester D. Adult soft tissue sarcomas. A pattern of care survey of the American College of Surgeons. Ann Surg. 1987 Apr;205(4):349-59.

5 Lee SE, Kim YJ, Kwon MJ, Choi DI, Lee J, Cho J et al. High level of CDK4 amplification is a poor prognostic factor in well-differentiated and dedifferentiated liposarcoma. Histol Histopathol. 2014 Jan;29(1):127-38.

6 Singer S, Antonescu CR, Riedel E, Brennan MF. Histologic subtype and margin of resection predict pattern of recurrence and survival for retroperitoneal liposarcoma. Ann Surg. 2003 Sep;238(3):358-70.

7 Neuhaus SJ, Barry P, Clark MA, Hayes AJ, Fisher C, Thomas JM. Surgical management of primary and recurrent retroperitoneal liposarcoma. Br J Surg. 2005 Feb;92(2):246-52.

8 Lemeur M, Mattei JC, Souteyrand P, Chagnaud C, Curvale G, Rochwerger A. Prognostic factors for the recurrence of myxoid liposarcoma: 20 cases with up to 8 years follow-up. Orthop Traumatol Surg Res. 2015 Feb;101(1):103-7.

9 Zhang WD, Liu DR, Que RS, Zhou CB, Zhan CN, Zhao JG et al. Management of retroperitoneal liposarcoma: A case report and review of the literature. Oncol Lett. 2015 Jul;10(1):405-9.

10 Na JC, Choi KH, Yang SC, Han WK. Surgical experience with retroperitoneal liposarcoma in a single korean tertiary medical center. Korean J Urol. 2012 May;53(5):310-6.

11 Leu KM, Ostruszka LJ, Shewach D, Zalupski M, Sondak V, Biermann JS et al. Laboratory and clinical evidence of synergistic cytotoxicity of sequential treatment with gemcitabine followed by docetaxel in the treatment of sarcoma. J Clin Oncol. 2004 May;22(9):1706-12.

12 Maki RG, Wathen JK, Patel SR, Priebat DA, Okuno SH, Samuels B et al. Randomized phase II study of gemcitabine and docetaxel compared with gemcitabine alone in patients with metastatic soft tissue sarcomas: results of sarcoma alliance for research through collaboration study 002 [corrected]. J Clin Oncol. 2007 Jul;25(19):2755-63.

13 Hensley ML, Maki R, Venkatraman E, Geller G, Lovegren M, Aghajanian C et al. Gemcitabine and docetaxel in patients with unresectable leiomyosarcoma: results of a phase II trial. J Clin Oncol. 2002 Jun;20(12):282431.

14 Verschraegen CF, Arias-Pulido H, Lee SJ, Movva S, Cerilli LA, Eberhardt S et al. Phase IB study of the combination of docetaxel, gemcitabine, and bevacizumab in patients with advanced or recurrent soft tissue sarcoma: the Axtell regimen. Ann Oncol. 2012 Mar;23(3):785-90.

15 Jones RL, Fisher C, Al-Muderis O, Judson IR. Differential sensitivity of liposarcoma subtypes to chemotherapy. Eur J Cancer. 2005 Dec;41(18):2853-60. 


\section{Case Reports in Oncology}

\begin{tabular}{l|l}
\hline Case Rep Oncol 2018;11:341-346 \\
\hline DOI: 10.1159/000489393 & $\begin{array}{l}\text { @ 2018 The Author(s). Published by S. Karger AG, Basel } \\
\text { www.karger.com/cro }\end{array}$ \\
\hline
\end{tabular}

Da Silva et al: Complete Remission of Recurrent Retroperitoneal Liposarcoma after the Administration of Gemcitabine and Docetaxel as First-Line Adjuvant Chemotherapy
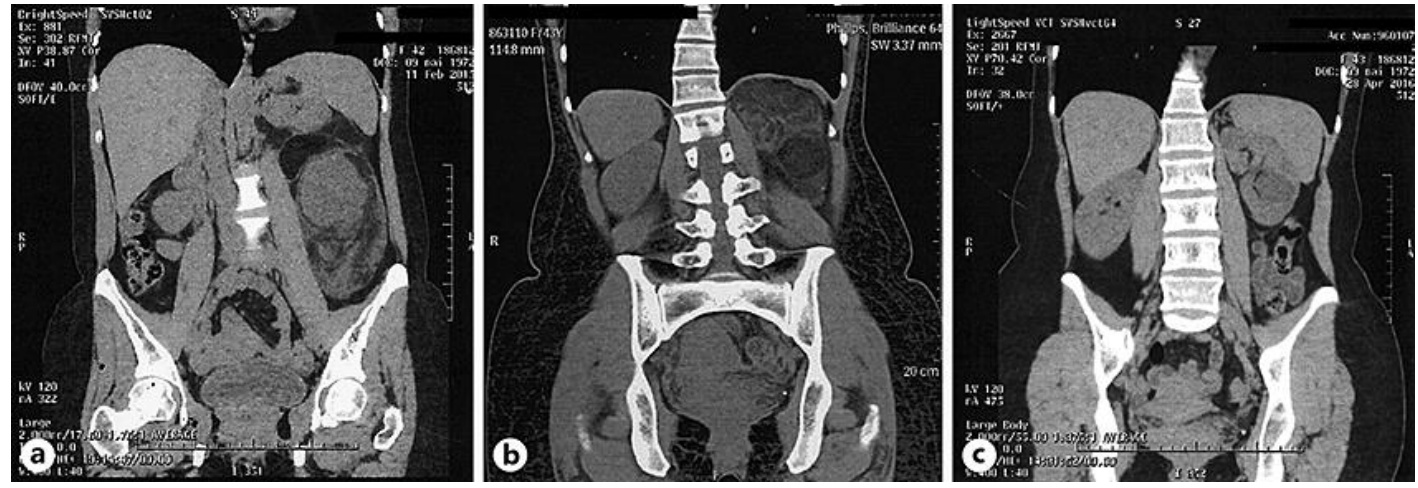

Fig. 1. a Abdominal computed tomography (CT) before the first surgery. b Abdominal CT after local recurrence. c Abdominal CT during cure follow-up.

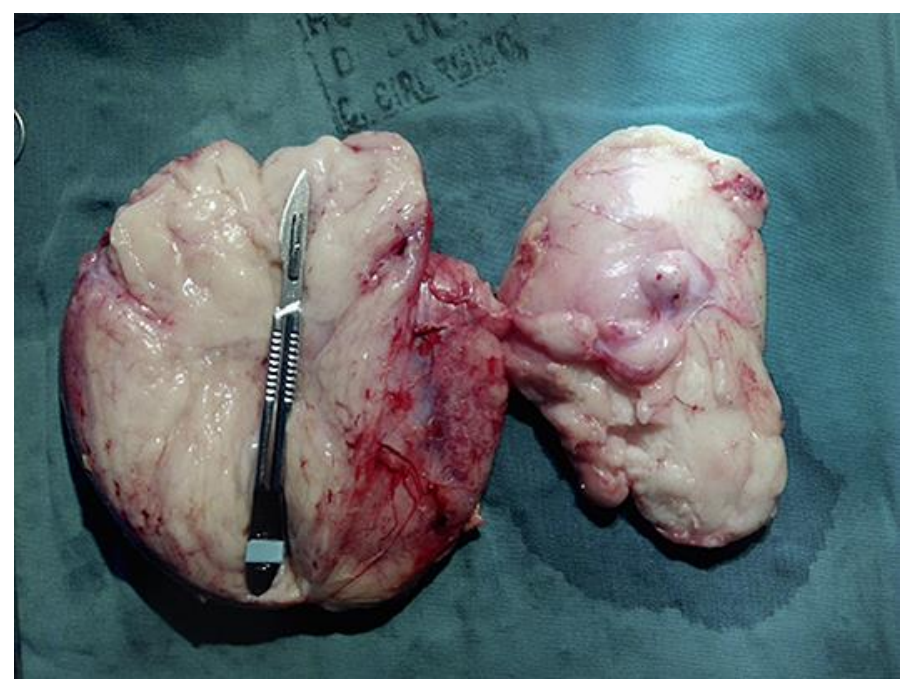

Fig. 2. Resected specimen of the first surgery. 


\section{Case Reports in Oncology}

\begin{tabular}{l|l}
\hline Case Rep Oncol 2018;11:341-346 \\
\hline DOI: 10.1159/000489393 & $\begin{array}{l}\text { ○ 2018 The Author(s). Published by S. Karger AG, Basel } \\
\text { www.karger.com/cro }\end{array}$ \\
\hline
\end{tabular}

Da Silva et al:: Complete Remission of Recurrent Retroperitoneal Liposarcoma after the Administration of Gemcitabine and Docetaxel as First-Line Adjuvant Chemotherapy

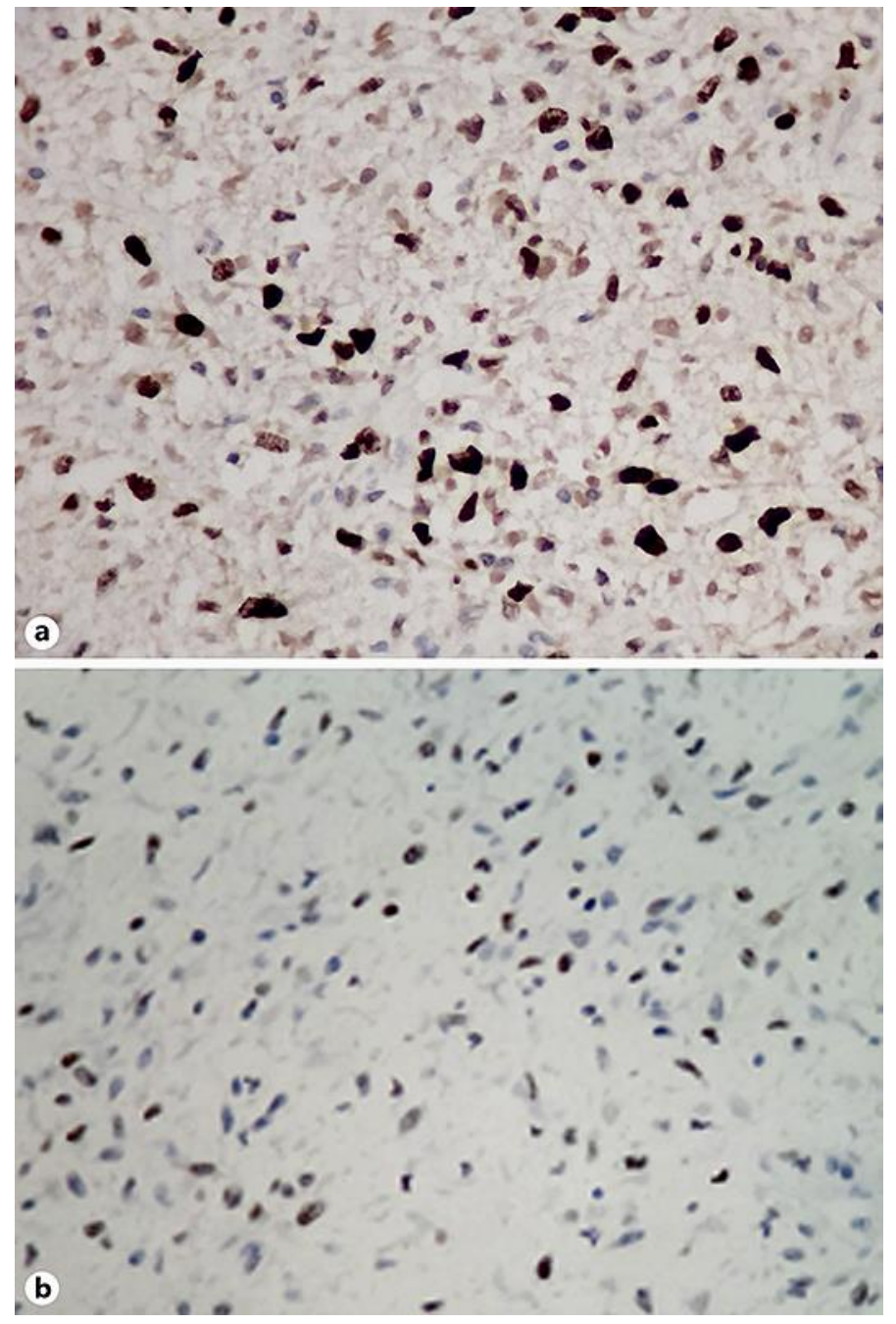

Fig. 3. a Immunohistochemistry with ki- $67, \times 400$. b Immunohistochemistry with $S-100, \times 400$. 